\title{
Critical Success Factors to Improve the Adoption of Social Media in Teaching and Learning: A Case Study at a Traditional University
}

\author{
https://doi.org/10.3991/ijim.v13i03.8485 \\ Obrain Tinashe Murire $\left.{ }^{(}\right)$ \\ Walter Sisulu University, East London, South Africa \\ otmurire2011@gmail.com \\ Liezel Cilliers \\ University of Fort Hare, East London, South Africa
}

\begin{abstract}
Mobile devices and social media tools are two emerging technologies that have positively influenced teaching and learning practices at traditional universities. Regardless of the popularity of social media, few lecturers make use of these tools for educational purposes. The objective of this paper was to identify critical success factors to improve the adoption of social media among lecturers at a traditional university in South Africa. The unified theory of acceptance and use of technology (UTAUT) was chosen as the theoretical foundation for this study. A quantitative, survey data collection method was used to collect data. A questionnaire was distributed to all academics at the university, with a response rate of $39 \%$. From these, descriptive statistics were used to analyse data and the Pearson chi-square test was used to establish the association amongst different variables. The following CSFs were identified to enhance emerging technologies at traditional universities: management support; provide adequate ICT infrastructure and resources; provide sufficient training for lecturers, and introduce a champion to promote social media. The study, therefore, recommends that these four critical success factors must be considered by universities to adopt social media in teaching and learning.
\end{abstract}

Keywords-Barriers to social media adoption; teaching and learning; higher education.

\section{Introduction}

Mobile devices and social networking sites are two emerging technologies that can positively influence teaching and learning practices at traditional universities. Initially, social media was employed by both lecturers and students for personal use only; however, the technology has now advanced to include other domains as well [1]. Universities are using social media platforms to maintain alumni relations, increase institutional reputation and pride, as well as to increase student - lecturer interaction. However, the slow pace of social media adoption at universities may be attributed to 
the barriers that avert the incorporation of emerging technologies in the academic environment [2-3]. Stephanie and Vladlena [4] state that lecturers need to know the barriers that prevent social media adoption in higher education to be in a better position to find effective strategies to overcome these barriers.

The objective of this paper is to provide critical success factors (CSF) to increase social media adoption and continued use among lecturers for teaching and learning activities at universities. For this reason, the study of barriers to social media adoption is important to enhance social media adoption and continued use at universities. The paper is outlined as follows: The first section discusses the literature followed by the methodology used in this study. The following section introduces the UTAUT which is followed by a discussion of the results and after that the contribution of the study and conclusion.

\section{Benefits of Social Media in Teaching and Learning}

Social media, for instance, Facebook, Twitter and wikis, along with open social practices, for example, blogging, are useful in teaching and learning environments in diverse ways [3]. These tools provide convenient communication, collaboration and sharing of information with peers in the classroom, subject experts and peers outside the class $[2,5]$. Additionally, the use of numerous social media tools is attractive at universities to improve student - lecturer interaction. Social media enables discussion and information diffusion amongst students and lecturers, thereby building a common understanding of the course material [6]. The following section discusses barriers to social media adoption in academia.

\section{Barriers to Social Media Adoption in Teaching and Learning}

Several barriers prevent lecturers from adopting social media in the classroom. The seven barriers that were identified by the researcher in literature will be discussed below.

\subsection{Inadequate ICT resource and data costs}

Almeshal [3] reveals that some lecturers find it challenging to utilise social media in teaching activities because there is a shortage of ICT infrastructure at universities, e.g. not all classrooms have computers. This result is supported by Schlenkrich and Sewry [7] who found that most students enrolled at universities access social networking sites in the university computer laboratories and libraries. Some students do make use of their mobile phones, but prohibitive data cost is always a concern. South Africa is one of the most expensive countries on the African continent when the cost of data is compared $[3,6]$. Therefore, mobile data is a luxury for many students in the country, and it is not reasonable or sustainable to expect students to pay for their data. 


\subsection{Availability of social media at universities}

Social media and other recreational sites are often blocked in computer laboratories at universities as a precaution to improve network speed and the productivity of students $[2,8]$. This constraint does not allow lecturers to experiment with different types of teaching and learning tools in class as students must have continuous access to social media if they intend to use it in the classroom.

\subsection{Computer and technology literacy skills}

Literature indicates that the technology literacy of both lecturers and students are important to adopt social media in the academic setting [9-10]. Technology literacy refers to an individual capacity to "design, develop and control use and assess technological systems and processes" [11, p. 7]. Gualtieri et al. [5], Stephanie, and Vladlena [4] found that the most important barrier to social media adoption and continued use is the lecturer's computer and technology literacy skills.

Oye, Iahad and Rahim [9] describe computer literacy skills as the "ability to use computers and related technology efficiently, with a range of skills covering levels of applying ICT effectively as a tool to research, organise, evaluate and communicate information" (p. 98). Researchers postulate that the expertise to adopt social media in the academic environment at universities is enhanced by effective technology training which must be hands-on, systematic and continuous [5]. Thus, computer literacy skills are a requirement for the implementation of social media tools in the academic environment.

\subsection{Background of the learners}

Murire and Cilliers [2] state that some students are not exposed to emerging technologies because they had previously resided in rural areas with no access to technological devices or the Internet. For this reason, students may not be familiar with specific social media applications that could be used for academic courses. Lecturers must provide training, support and encouragement to the students to make use of the technology.

\subsection{Attitude and beliefs towards social media use at universities}

The adoption of social media in academic settings is primarily determined by lecturers' attitudes and beliefs [3]. Thus, lecturers influence the choice of and determine how social media could be used in the classroom. Bexheti et al. [1] found that a lecturer's attitude is a major enabling or disabling factor in the adoption of social media in teaching and learning. Lecturers who have positive attitudes towards social media are comfortable incorporating it into their teaching and learning.

Successful transformation of social media in academic environment environments needs lecturers to develop a positive attitude towards emerging technologies [3]. The development of lecturers' positive attitudes toward ICT is a key factor for enhancing 
social media integration as well as reducing educators' resistance to emerging technologies used in teaching and learning.

\subsection{Lack of management support}

One of the institutional barriers is a lack of managerial support for social media integration in the academic setting. Managerial support may be the most critical factor as it provides the needed financial resources, develops a vision and plan for social media integration, and provides incentives and encouragement [5]. Furthermore, university management needs to prioritise, create awareness and set an expectation that emerging technologies, such as social media, must be used in the academic environment. Management must prioritise social media integration cost to support the training of lecturers on how to integrate social media into their teaching pedagogy. If university management places a strong emphasis on social media adoption, the result will be increased student - lecturer interaction, student centred learning, and improvement in throughput rates $[3,12]$. Additionally, when universities do not take time to develop a policy on social media in the classroom, lecturers and students will be confused regarding when it is appropriate to use these emerging technologies [13].

\subsection{Online security and privacy}

Some students perceive social networking sites as their personal space and do not want their studies to intrude in this space. The students' often cite privacy concerns as a reason why they do not want to participate in social media activities in the classroom. While there are security measures available online to protect the individual's privacy, there is no guarantee that students are aware of these measures or will make use of them [14]. Consequences that could result from the use of social media in the academic setting include identity theft, online and physical stalking, cyberbullying, as well as defamation [6, 14]. Regardless of these concerns, lecturers believe that social media sites are valuable in the teaching and learning environments. The next section discusses the theory employed in the study.

Unified Theory of Acceptance and Use of Technology: The unified theory of acceptance and use of technology (UTAUT) was chosen as the theoretical background for this study. UTAUT was developed initially by Venkatesh, Morris, Davids, and Davis in 2003 and is one of the most cited theories in information systems $[15,6]$.

UTAUT is based on four primary constructs:

- Performance expectancy is the degree to which lecturers will perceive that using the social media will help them improve work performance in the academic environment.

- Effort expectancy the degree of effort that lecturers perceive they need to adopt and use social media in the academic environment. 
- Social influence is described as the degree to which lecturers perceive that important external parties, such as peers or management, believe they should use social media in the classroom.

- Facilitating conditions refers to the degree to which organisational and technical infrastructure at universities exist to support the use of social media in the classroom. Additionally, these constructs are moderated by four facilitating conditions: experience, age, gender, and voluntariness of use. The following section discusses results from the study [16].

\section{$4 \quad$ Research Methodology}

The study applied a mixed method approach to data collection. Both qualitative and quantitative data gathering methods were used to complement each method. Inductive reasoning was applied to the study. A quantitative survey tool was used to collect the data from lecturers at one university in the Eastern Cape. The questionnaire was adapted from the original questionnaire that Venkatesh et al. [16] published to test for the acceptance and continued use of new technologies. The questions were adapted to reflect the social media context of the study.

The study population comprised of 200 full-time staff in all the faculties of the university. A convenience sampling method was used to identify and distribute the questionnaire online to all lecturers. Before this, the questionnaire was piloted to 10 lecturers, who were not included in the primary study, for suitability, user-friendliness and unambiguousness. Ethical approval was obtained from the University Research Ethics Committee.

The Statistical Package for the Social Science (SPSS 24) was used to analyse the primary data. Descriptive and inferential statistics, including the Pearson chi-square test, was applied to analyse the data collected using questionnaire from the research participants.

After the critical success factors were formulated, an open-ended questionnaire was sent to five experts in the field of technology integration in the academic environment in higher education to elicit their opinions about the factors. The feedback received was used to refine the critical success factors. The following section discusses results of the study.

\section{$5 \quad$ Results and Discussion}

\subsection{Demographics}

The response rate of the study was $39 \%$. The study participants consisted of $54.2 \%$ female and $45.8 \%$ male lecturers. Lecturers were requested to rate their knowledge of teaching and learning. The majority of the lecturers indicated that they are moderate to very knowledgeable $(79.5 \%)$, while $20.5 \%$ stated that they are incredibly 
knowledgeable about teaching and learning. No lecturers felt that they were not knowledgeable at all about teaching and learning.

\subsection{Age of lecturers}

The age groups were divided into four categories: under 30 years of age, between 30 - 40, 41-50, and over 50 years of age. The distribution shows that the $41-50$ years age population consisted of the majority of the lecturers $(39.8 \%)$, followed by the $30-40$ year age group with $34.9 \%$. The lecturers that were younger than 30 years of age and older than 50 years of age each were less than $15.0 \%$ of all the lecturers combined. The findings of the study are not congruent to statistics of age ratio of the academic population in South Africa. Bezuidenhout and Cilliers [17] state that more than $50 \%$ of the academic staff at South African higher education institutions is above 50 years of age and approaching their retirement time. Therefore, this means that younger lecturers responded as they are more receptive to using new technologies in the academic environment. The age groups of lecturers are presented in Table 1.

Table 1. Lecturers' age groups

\begin{tabular}{|c|c|c|}
\hline Age Group & Frequency $\mathbf{( N = 8 3 )}$ & Percentage (\%) \\
\hline$<30$ & 9 & 10.8 \\
\hline $30-40$ years & 29 & 34.9 \\
\hline $41-50$ & 33 & 39.8 \\
\hline$>50$ & 12 & 14.5 \\
\hline Total & $\mathbf{8 3}$ & $\mathbf{1 0 0 . 0}$ \\
\hline
\end{tabular}

More than half of the lecturers were older than 41 years of age. In general, the older generations find it more challenging to adopt new technology which will affect the use of social media in the academic setting [18]. Venkatesh et al. [16] confirm that age influences the integration of emerging technologies. It is believed that younger adults are more computer literate because they are familiar with technology in their everyday lives [14].

Lecturers were asked how frequently they used social media in the academic environment. The majority of the lecturers $(33.7 \%)$ reported that they use social media occasionally, while $22.9 \%$ indicated that they have never used social media tools in academia. Only 15 lecturers, or $18.1 \%$, reported that they use social media tools on a daily basis.

Table 2. Frequency of social media tools in teaching and learning

\begin{tabular}{|l|c|c|}
\hline \multicolumn{1}{|c|}{ Use of social media } & Frequency $(\mathbf{N}=\mathbf{8 3})$ & Percentage (\%) \\
\hline Daily & 15 & 18.1 \\
\hline Once a week & 6 & 7.2 \\
\hline Once a month & 15 & 18.1 \\
\hline Occasionally (when I cannot avoid it) & 28 & 33.7 \\
\hline Never & 19 & 22.9 \\
\hline Total & 83 & 100.0 \\
\hline
\end{tabular}


The results indicated that most lecturers are not utilising social media in teaching and learning for academic purposes although they know social networking sites. This could be a personal preference of the lecturer or because of the nature of the specific courses where social media is not considered to be useful. Different teaching styles in the various faculties may not be compatible with social media, e.g. Mathematics or Accounting that is practical.

\subsection{Performance expectancy}

In this study, $92.7 \%$ of the lecturers were positive that social media supports teaching and learning as well, as improves their productivity in the classroom. Performance expectancy also tested significantly for both the age and gender. The questions that proved significant were:

- "I feel that social media will support teaching and learning" was statistically significant $(\alpha=25.818 ; \mathrm{p}<0.05)$

- "Using social media for teaching and learning enables me to be more productive" was statistically significant $(\alpha=29.973 ; \mathrm{p}<0.05)$

- "Using social media for teaching and learning enables me to be more productive" was statistically significant $(\alpha=25.355 ; \mathrm{p}<0.05)$

Performance expectancy on intention to use social media was moderated by gender and age such that it is more significant for female and older employees, but these influences decrease as the older female participants gain more experience with the technology. Furthermore, the majority of the study population consisted of lecturers who are older than 41 years of age. As pointed out previously, the older generation finds it challenging to adopt the technology, and this influences the use of social media in the academic setting [16].

Furthermore, these findings are similar to the results obtained from a study conducted by Mbodila, Ndebele, and Muhandji [19] at the University of Venda. The researchers reported that performance expectancy is the most influential factor of social media use in the academic setting, as social media will assist the lecturer to improve their job performance. This could allow an increase in the lecturer's integration of emerging tools in the academic environment in teaching and learning since general information technologies are included. The findings from the study are comparable to the results in research $[1,9]$ where effort expectancy was found to be among the factors influencing lecturers to incorporate emerging technologies in academia.

\subsection{Effort expectancy}

The majority of the lecturers $(71.1 \%)$ indicated that social media is easy to use for teaching and learning purposes. The results indicated that all the lecturers are knowledgeable about teaching and learning. Additionally, the lecturers $(60.3 \%)$ were positive that their interaction with social media in academia is clear and understandable. Interestingly, $39.7 \%$ of the lecturers felt that it would be difficult to learn how to make 
use of social networking sites in the classroom. However, once the initial learning curve is overcome, most lecturers agree that social media is easy to use for teaching and learning activities. No question tested statistically significant in this category.

Effort expectancy was found to be among the factors influencing lecturers to adopt social media in the academic setting. The results indicated that some of the lecturers are adopting social media because it is comfortable to use and familiar to them [20]. This is one of the reasons for using emerging technologies like Facebook, Twitter and Whatsapp as lecturers are familiar with the application.

\subsection{Social influence}

More than half of the lecturers $(54.2 \%)$ felt that they are influenced by others (colleagues) to employ social media. In contrast, just more than half of the lecturers $(54.3 \%)$ indicated that the senior management did not support the use of emerging technologies in the academic environment. Social expectancy tested significantly for both the age of lecturers and their reported knowledge about using social media. The three questions that tested significantly were:

- "People who influence my behaviour think I should use social media for teaching and learning activities" was statistically significant for social influence ( $\alpha=26.582$; $\mathrm{p}<0.05)$

- "People who influence my behaviour think I should use social media for teaching and learning activities was statistically significant for social influence $(\alpha=12.754$; $\mathrm{p}<0.05)^{\prime \prime}$

- "In general the Department of Higher Education supports the use of social media in teaching and learning" was statistically significant $(\alpha=19.435 ; p<0.05)$

The findings show that the Department of Higher Education needs to support the use of emerging technologies in the academic setting. The results indicated that more than half of the lecturers $(54.2 \%)$ felt that they are influenced by others (colleagues) to use social media. For that reason, it was concluded that the lecturers below the age of 30 years could affect senior lecturers and professors to integrate social media in the academic setting. However, the majority of the lecturers $(54.3 \%)$ indicated that the senior management did not support the use of emerging technologies in the academic environment. Moreover, these findings are similar with the outcomes from a previous study done by Oye et al. [9] where social influence was indicated as one of the predictors of lecturers to integrate ICT in institutions.

\subsection{Facilitating condition}

The majority of lecturers $(71.1 \%)$ were positive that they have the resources necessary to use social media in academia. However, $49.4 \%$ of the lecturers were not convinced that social media is compatible with their other lecturing responsibilities, which could be attributed to the lack of training the lecturers reported. The faculty was measured against facilitating condition and the question "Using social media for 
teaching and learning is not compatible with other lecturing responsibilities that I have" was statistically significant $(\alpha=21.683 ; p<0.05)$.

The findings from the study indicate that the facilitation condition influences social media use in the academic setting. Lecturers recognise that institutional and technical infrastructure exists to encourage the use of emerging technologies in the academic setting. Some faculties do not use social media as it is not compatible with the structure of their module. In faculties like Law and departments like Accounting, teaching and learning activities require a "hands-on" approach in the classroom where social media will not be useful. However, the technology can still be used outside the classroom to collaborate and increase communication among students and lecturers.

These findings are congruent with the results from a study done by Mbodila et al. [19] that found that facilitating condition was the most influential predictor of lecturers' use of Facebook in the academic environment. The majority of lecturers $(73.5 \%)$ were positive that they would adopt emerging technologies in their academic activities shortly. Similarly, $71.1 \%$ of the lecturers expect to use social media in teaching and learning in the next 12 months. Furthermore, a majority of the lecturers (75.9\%) plan to employ emerging technologies in academia in the next 12 months. This is because they found that social media is a useful tool, and most of the lecturers are knowledgeable about social media. The next section will discuss critical success factors.

\section{Critical Success Factors}

The study aimed to find Critical Success Factors (CSF) that are necessary to ensure the adoption and continued use of social media in teaching and learning at universities. Olszak and Ziemba [21] describe CSFs as aspects of a strategy that ought to be achieved to yield a favourable outcome of the study. The CSFs identified from the relevant literature were refined by the experts in teaching and learning. An openended questionnaire was sent to five experts who provided an extensive critical review of how the proposed CSFs could change the adoption of social media in teaching and learning. Their feedback was used to refine the final CFSs. These CSFs will be discussed in the next section.

\subsection{CSF 01 - Management support}

As identified in the discussion section, there is little support from management to use social media in the classroom The adoption which is taking place at the particular university is dependent on individual lecturer's willingness to use the technology. However, the majority (75.9\%) of the lecturers plan to employ social media in academia in the next 12 months. Lubega et al. [22] indicate there is a need for management to provide adequate support to lecturers that are planning to integrate social media into the academic setting. The management requires a social media policy in place to govern the use of emerging technologies in the academic setting by lecturers in the teaching and learning environment. 
Apart from social media policy, the university management should ensure that appropriate privacy and security measures are in place to protect personal information. Literature has indicated that there are concerns about security and privacy of students' profiles. While most universities do have a policy in place to protect students' privacy when using the university network, there is a need for a specific social media policy to protect students' profiles [10]. This is supported by Schlenkrich and Sewry [7] who state that the policies and standards must be in place to manage security risks associated with social media tools.

The university management should ensure that there is a group responsible for auditing, such as the ICT Governance Committee, in place to evaluate if lecturers are using emerging tools in the academic setting. Additionally, the auditing group must put in place measures to penalise lecturers failing to integrate and incentives for those that are incorporating ICT in pedagogy [22].

Also, university management should consider the use of social media through faculty appraisal. Universities do not have incentives to reward lecturers that have innovatively integrated social media in their teaching as role models to others. Nonmonetary incentives, such as ICT devices, certificates of recognition and employee of the year awards, should be used to recognise lecturers that are employing social media in teaching and learning at universities [23].

\subsection{CSF 02 - Provide adequate resources for social media use}

The majority (68.7\%) of the lecturers indicated that they do not have sufficient resources necessary to make use of social media in teaching and learning. Shortage of infrastructure and technical assistance has a negative impact on the adoption and continued use of social media in teaching and learning. The university management must have a comprehensive budget for ICT infrastructure that supports sustained interest in the use of the social media in the teaching and learning environment at universities.

The integration of emerging tools in the academic setting requires policymakers to make informed choices when introducing social media learning at universities. The management may choose to incorporate low-cost technologies into development efforts, as they are readily available. Sustainability and maintenance of the physical infrastructure should be taken into account, as social media learning requires continuing financial assistance [22].

Lecturers stated that low bandwidth is one of the reasons for not using emerging technologies in academic activities. Management should prioritise students and lecturers' ICT infrastructure within the institutions [2, 6 and 22]. Also, universities should encourage lecturers and students to make use of their computing devices such as laptops, mobile phones and tablets, as well as strengthening Wi-Fi hotspots at campus and residence where students can access the Internet [24]. 


\subsection{CSF 03 - Provide adequate training for lecturers}

The lecturers indicated that they do not have sufficient knowledge and technology supported pedagogy skills to employ social media in teaching and learning. Providing proper training and support will allow lecturers to be prepared with the necessary information and pedagogical skills required to incorporate social media into the teaching environment. This could be achieved by encouraging lecturers to complete computer literacy courses and the Post Graduate Diploma in Higher Education for them to become more technically skilful and comfortable with social media tools in teaching and learning [23]. Therefore, university management must organise seminars and workshops regularly to enhance the faculties' knowledge on how to use social media in the academic environment.

Some of the lecturers have completed the training alone without the help of the university as they seek to improve their teaching skills. Universities ought to mobilise lecturers with these skills to train their colleagues (CSF 04 - Introduce a champion). The university management must prioritise education of lecturers in the educational technology related fields [22]. Therefore, lecturers will feel comfortable to include social media in their teaching practices.

\subsection{CSF 04 - Introduce a champion}

All the stakeholders in the teaching and learning field should be involved to ensure the successful implementation of social media at universities. Typical activities include education, raising awareness and engagement with the lecturers who will be making use of social media in the academic setting [25]. Social influence from colleagues was found to be influential (54.2\%) towards the use of social media in the academic setting. Introducing a champion is one of the techniques that could be used to facilitate the integration and continued use of social media in the academic environment, as the objectives of making use of the technology will be communicated.

The findings of the study indicated senior management do not influence the lecturers, but colleagues could be used as champions. The champion must communicate with the different stakeholders such as the university management and academic staff. Thus the champion can act as a catalyst for innovation. Additionally, the champion can serve as an individual with knowledge and the understanding of the necessary social media technologies as well as the ability to embrace the objectives, thereby supporting technology-based solutions towards achieving excellent results. Thus, the champion should render assistance to lecturers and faculties facing challenges in using social media in the academic setting. The next section discusses the contribution of the study.

\section{Conclusion}

Mobile devices and emerging technologies play a vital role in academic activities at universities. Irrespective of the high popularity of social media for personal use, a low percentage of students and lecturers use them for educational purposes. The study has 
highlighted that adopting social media in teaching and learning results in an improved throughput rate, student-lecturer interaction, student-centred learning and collaboration and student engagement. The research study set to develop CSFs to enhance lecturers' adoption and continued use of social media at universities.

The CSFs developed are the primary contribution of this study. The following CSFs were identified to enhance social media in the academic environment: Provide adequate resources, management support, introduce a champion, and provide sufficient training for lecturers. These CSFs were developed taking into account the various aspects that could hinder successful incorporation of emerging technologies in the academic environment.

One of the constraints to the research study is that data was collected from one traditional university, assuming that all universities in South Africa have the same teaching and learning context as this university. The sample size was small. Additionally, a survey method was employed in the research study. Therefore results are only based on quantitative data, and thus there was no follow up with qualitative interviews. Future research on adoption of social media in the teaching and learning environment in South Africa must draw a large sample including at least one traditional university from each province in South Africa.

\section{References}

[1] Bexheti, L. A., Ismaili, B. E., \& Cico, B. H. (2014). An Analysis of Social Media Usage in Teaching and Learning: The Case of SEEU. Recent Advances in Electrical and Computer Engineering, 90 - 94.

[2] Murire, O. Cilliers, L. (2016). Social media adoption among lecturers at a traditional university in

[3] Eastern Cape Province of South Africa. South African Journal of Management, 19, (1), 1- 6

[4] Almeshal, T. (2015). Social Media Adoption in Learning and Teaching by Higher Education Faculty. 9th International Technology, Education and Development Conference (pp. 1- 10). Madrid: Higher Education Faculty.

[5] Stephanie, M., \& Vladlena, B. (2014). Barriers to the Adoption of Social Technologies in Higher Education. 1-4. Retrieved from https://www.srhe.ac.uk/conference2014/abstracts/0136.pdf

[6] Gualtieri, L., Javetski, G., \& Corless, H. (2015). The Integration of Social Media into Courses: A Literature Review and Case Study from Experiences at Tufts University School of Medicine. Academia, 1- 9.

[7] Cilliers, L. (2016). Wiki acceptance by university students to improve collaboration in Higher Education. Innovations in Education and Teaching International, 1- 9, DOI:

[8] 10.1080/14703297.2016.1180255.

[9] Schlenkrich, L., \& Sewry, D. A. (2012). Factors for Successful Use of Social Networking Sites in Higher Education. SACJ, 49, 12- 24. https://doi.org/10.18489/sacj.v49i0.78

[10] Chetty, P., \& Law, C. (2014). The top 5 Intellectual Property Risks on Social Media. Retrieved October

[11] 01, 2015, from southafrica.smetoolkit.org:

[12] http://southafrica.smetoolkit.org/sa/en/content/en/51103/The-top-5-Intellectual-Property risks-onsocial-media 
[13] Oye, N. D., Iahad, N. A., \& Rahim, N. A. (2014). The history of UTAUT model and its impact on ICT acceptance and usage by academicians. Education Information Technology, 19, 251-270. https://doi.org/10.1007/s10639-012-9189-9

[14] University of Massachusetts Dartmouth. (2013). Social Media Adoption Research in Higher Ed. London: a longitudinal study of social media adoption in higher ed. Retrieved from http://www.uversity.com/blog/social-media-adoption-in-higher-ed/

[15] Shackelford, R., Brown, R., \& Warner, S. (2004). Using concepts and theoretical models to support the standards for technological literacy. Technology Teacher, 63, 5, 7-11.

[16] Kinuthia, W. (2015). Learning Design for Personal Learning Environments: Engaging Emerging Technologies to Transform Online and Blended Instruction in African Higher Education. Computer \& Technology, 1- 8.

[17] Batikas, M., Bavel, R., Martin, A., \& Maghiros, I. (2013). Use of Social Media by European SMEs.

[18] Retrieved from http://www.europski-

[19] fondovi.eu/sites/default/files/dokumenti/KK0113565ENN_002.pdf

[20] Chinyamurindi, W., Cilliers, L., Viljoen, K. (2017). A study on students' acceptance of using mobile phones to seek health information in South Africa. Accepted in Health Information Management Journal. https://doi.org/10.1177/1833358317706185

[21] Khechine, H., Lakhal, S., Pascot, D., \& Bytha, A. (2014). UTAUT model for blended learning: the role of gender and age in the intention to use webinars. Interdisciplinary Journal of E-Learning and Learning Objects, 10, 33-52. https://doi.org/10.28945/1994

[22] Venkatesh, V., Morris, M., Davids, G., \& Davis, F. (2003). User Acceptance of Information Technology: Toward a unified view. MIS Quarterly, 27, 3, 425-478. https://doi.org/10. $\underline{2307 / 30036540}$

[23] Bezuidenhout, A., \& Cilliers, F. (2011). Age, burnout, work engagement and sense of coherence in female academics at two South African universities. South African Journal of Labour Relations, 35, 1, 61- 80.

[24] Arthur, J. K., Adu-Manu, K. S., \& Yeboah, C. (2013). A conceptual framework for the Adoption of Social Network Technologies (SNTs) in Teaching - a case of Ghana. International Journal of Computer Science Issues, 10 (5), 2, 70-78.

[25] Mbodila, M., Ndebele, C., \& Muhandji, K. (2014). The Effect of Social Media on Student's Engagement and Collaboration in Higher Education: A Case Study of the Use of Facebook at a South African University. J Communication, 5 (2), 115 - 125. https://doi.org/10.1080/0976691X.2014.11884831

[26] Wiid, J. A., Nell, C. E., \& Cant, M. C. (2015). Perceptions of Lecturing Staff on Social Media Networking Systems and their use of it. International Business \& Economics Research Journal, 14 (3), 395- 410. https://doi.org/10.19030/iber.v14i3.9204

[27] Olszak, C. M., \& Ziemba, E. (2012). Critical Success Factors for Implementing Business Intelligence Systems in Small and Medium Enterprises on the Example of Upper Silesia, Poland. Interdisciplinary Journal of Information, Knowledge, and Management, 7, 129 -150. https://doi.org/10.28945/1584

[28] Lubega, J. T., Mugisha, A. K., \& Muyinda, P. B. (2014). Adoption of the SAMR Model to Asses ICT Pedagogical Adoption: A Case of Makerere University. International Journal of e-Education, eBusiness, e-Management and e-Learning, e Learning - 115.

[29] Munguatosha, G. M., Muyinda, P. B., \& Lubega, J. T. (2011). A social networked learning adoption model for higher education institutions in developing countries. On the Horizon, 19 (4), 307-320. https://doi.org/10.1108/10748121111179439

[30] Madhav, N., Joseph, M. K., \& Twala, B. (2014). Creating Social Learning Spaces to Enhance the Learning Experience. 1-15. 
[31] Bingimlas, K. A. (2009). Barriers to the Successful Integration of ICT in Teaching and Learning Environments: A Review of the Literature. Eurasia Journal of Mathematics, Science \& Technology Education, 235-245. https://doi.org/10.12973/ejmste/75275

\section{Authors}

Mr Obrain Tinashe Murire is a lecturer in the Department of People Development and Technology at Walter Sisulu University. He received his Honours and Masters Degrees in Information Systems from the University of Fort Hare in 2014 and 2017 respectively. He is currently registered for D Phil in Information Systems Degree in the Department of Information Systems at the University of Fort Hare. His research interest includes information security and emerging technologies for employability as well as teaching and learning.

Dr Liezel Cilliers is an associate professor in the Department of Information Systems at the University of Fort Hare. She has completed a DPhil (Information Systems) in 2014 and is currently busy with a Master's degree in Education. In 2016, she was awarded the Vice Chancellor's Excellence award in the category of experienced Teacher, while she received the Vice Chancellor's Excellence award in the category emerging Researcher in 2015. She has established an e-health research group in the Faculty of Management and Commerce and was awarded a South African Medical Research Council grant in partnership with the Karolinska Institutet in Sweden as well a National Research Foundation Thuthuka grant.

Article submitted 2018-02-21. Resubmitted 2019-01-13. Final acceptance 2019-02-19. Final version published as submitted by the authors. 